\title{
Transhiyatal özofajektomi
}

\section{Transhiatal esophagectomy}

\author{
Ahmet Başoğlu \\ Ondokuz Mayıs Üniversitesi, Göğ̈̈s Cerrahisi Anabilim Dalı, Samsun, Türkiye
}

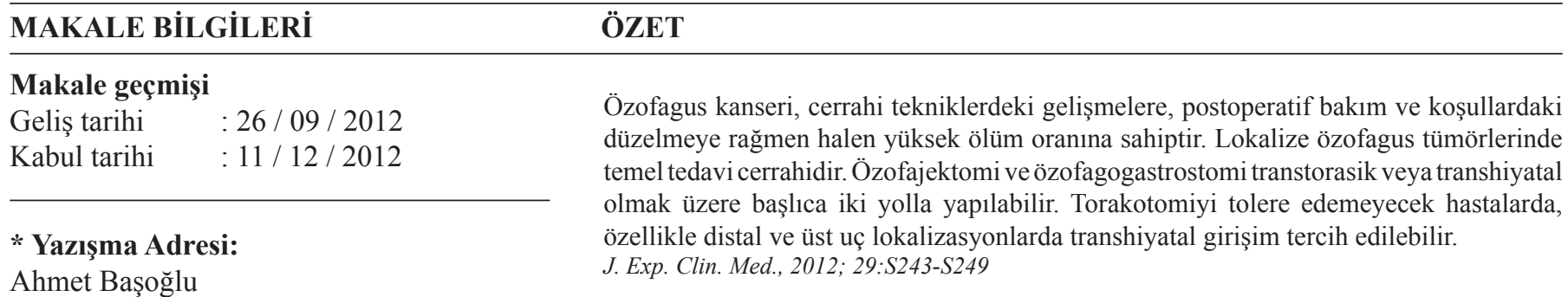

Ondokuz Mayıs Üniversitesi,

Göğüs Cerrahisi Anabilim Dalı,

Kurupelit, Samsun

e-posta: ahmetb@omu.edu.tr

\section{Anahtar Kelimeler:}

Özofagus

Kanser

Transhiyatal

Özofajektomi

Özofagogastrostomi

\section{Keywords:}

Esophagus

Cancer

Transhiatal

Esophagectomy

Esophagogastrostomy

\begin{abstract}
Although surgical techniques and postoperative and oncological care have improved, esophageal cancer still has a high mortality rate. The basic treatment for localized esophageal tumors is surgery. Esophagectomy and esophagogastrostomy could mainly be performed in two ways; transthoracic and transhiatal For patients who can not tolerate thoracotomy, transhiatal intervention is preferable, especially if the tumor is localized at the distal or high-end.

J. Exp. Clin. Med., 2012; 29:S243-S249
\end{abstract}

\section{Giriș}

Özofagus kanseri cerrahi tekniklerdeki gelişmelere, preoperatif ve postoperatif bakım ve koşullardaki düzelmeye rağmen halen yüksek ölüm oranına sahiptir. Sistemik kemoterapi (KT), radyoterapi (RT) ve artan oranda kabul gören multimodal tedaviyle son üç dekattır sağkalım uzamasına rağmen, lokalize özofagus tümörlerinde gerçek tedavi cerrahidir.

Hastaların çoğu anrezektabldır, sadece \% 30-40'ında rezeksiyon yapılabilmektedir (Birkmeyer ve ark., 2002). Özofajektomi için tanımlanan yaklaşımlar iki major başlık altında toplanır; transtorasik veya transhiyatal. Transtorasik yöntem genellikle laparotomi ve sağ torakotomi (Ivor Lewis yöntemi) ile yapılır. Ayrıca sol torakoabdominal insizyon veya servikal anastomozlu üç bölge insizyonu şeklinde (McKeown yöntemi) yapılır. Transhiyatal yaklaşımda orta hat laparotomi ve servikal insizyon gerekir. Kısa ve uzun dönem çok iyi sonuçları olan bu yöntem hakkında karşıt görüşler de vardır. Transhiyatal girişim, torakotomiyi tolere edemeyecek hastalarda, özellikle distal ve üst uç lokalizasyonlarda olmak üzere ve cerrahın deneyimine göre karar verilir (Barreto ve Posner, 2010).

Alman anatomist Denk 1913' de kadavralarda, özel alet ile posterior mediyastenden özofagusun çıkarılabileceğini öne sürdü (Denk, 1913).

İngiliz cerrah Grey Turner 1936' da abdominal ve servikal insizyonla özofagus kanserini rezeke ederek, antetorasik deri tüpü ile yutma restorasyonu sağladı (Orringer, 2006). Bu ameliyat transtorasik ameliyatların güvenle yapılmasına izin veren, endotrakeal anestezinin keşfinden önce yapıldı. Endotrakeal anestezi uygulanmaya başlandıktan sonra bu teknik 
terkedildi. 1970’ de birkaç yazar intratorasik özofagus hastalıkları için transhiyatal özofajektomiyi raporladı. Orringer ve Sloan (1978) de bu tekniği tekrar populer yaptı. 2,5 dekat sonra, transtorasik özofajektomiye alternatif olarak transhiyatal yöntemi yayınladı. 2000 üzerinde transhiyatal özofajektomi deneyimini yayınlayan Orringer benign veya malign hastalıklar için özofagus rezeksiyonu gereken hastaların çoğunda torakotominin gerekli olmadığını bildirdi. Özellikle distal özofagus adeno kanserlerinde transhiyatal özofajektomi cerrahlar tarafindan tercih edilmektedir.

Özofajektomi için transhiyatal yaklaşımın avantajları, mortalite ve morbiditeyi azaltmasıdır. Torakotomiden kaçınılan bu teknikte fizyolojik travma ve postoperatif ağrı azalır, böylece pulmoner komplikasyonlar önlenir (Orringer ve Sloan, 1978). Ameliyat süresi kısalır. Transhiyatal özofajektomide anastomoz servikal bölgede yapılır. Servikal anastomoz kaçağı genellikle servikal drenaj ve lokal yara bakımı ile tedavi edilir. Mediyastinit gelişmez. Dezavantajları; Transhiyatal özofajektomi ile üst ve orta özofagus tümörlerinde onkolojik prensiplere yeterince uyulamaz. Striktür oluşumu ile sonuçlanan anastomoz kaçağında artış ve yüksek reküren larinks sinir hasarı riski söz konusudur (Rindani ve ark., 1999; Hulscher ve ark., 2001).

Serilerde transhiyatal özofajektomiden sonra postoperatif mortalite \% 1 ve \% 7,5 arasındadır ve transtorasik girişimden daha azdır (Gelfand ve ark., 1992; Orringer ve ark., 2007). Beş yıllık sağkalım yaklaşık \% 25 olup, başarılı yapılmış transtorasik girişimden çok farklı değildir. Orringer ve ark. transhiyatal özofajektomi yaptıkları hastalardan oluşan geniş deneyimlerini 2007 yılında yayınladılar. Hastaların 1525'i özofagus kanseriydi ve beş yıllık sağkalım \% 29 olarak bildirildi. En son 944 hastadan oluşan serilerinde ise hastane mortalitesi \% 1 bulunmuştur. Anostomoz kaçağ1 \% 9, reküren larinks sinir hasarı \% 2 olarak bildirilmiştir. Sonuçlar diğer transhiyatal serilerle benzerdi (Orringer ve ark., 2007). Kliniğimizde özofagus rezeksiyonu yapılan hastaların \% 62' si transtorakal, \% 18,8' i transhiyatal yöntemle gerçekleştirildi. Transhiyatal ve transtorasik rezeksiyonların komplikasyonları karşılaştırıldığında sırasıyla pnömoni \% 18,8-\% 20,8; anastamoz kaçağı \% 9,4-\% 12,5; anastamoz darlığ $1 \%$ 6,3-\% 7,5 olarak tespit edilmiştir. Postoperatif mortalite transhiyatal özofajektomide \% 6,3; transtorakal özofajektomide \% 7,5 olarak bulundu. Bir yıllık sağkalım sırasıyla transhiyatal özofajektomide $\% 43$, transtorasik özofajektomide \% 39,3 bulundu.

Rindani ve arkadaşlarının (1999) transhiyatal ve transtorasik özfajektomileri karşılaştırdıkları metaanalizde; 19861996 yılları arasında 44 seri ve 5500 hasta vardı. Serilerden sadece biri prospektif randomize çalışmaydı. Prospektif çalışma küçük bir grupla yapılmış ve kısa süre izlenmiştir. Pulmoner ve kardiyak komplikasyonlar iki grup arasında benzerdi. Transhiyatal grupta anastomoz kaçağı ve larinks sinir hasarı daha fazla bildirilmiştir. Postoperatif mortalite transhiyatal grupta $\% 6,3$, transtorasik rezeksiyonda $\% 9,5$ bulundu. Fakat beş yıllık sağkalımda iki grup arasında fark görülmedi.

Hulscher ve arkadaşlarının (2001) metaanaliz çalışması 1990-1999 yılları arasında, 50 seriden oluşan 7525 hastay1 içeriyordu. Altısı prospektif, üçü randomize çalışmaydı. Gruplar az sayıda hasta içeriyordu. Randomize iki çalışmada da mortalite, morbidite ve sağkalımda gruplar arasında fark bulunmadı (Goldminc ve ark., 1993; Jacobi ve ark., 1997).
Transtorasik rezeksiyonda kan kaybı, pulmoner komplikasyonlar, şilöz kaçak ve yara yeri enfeksiyonu daha fazlaydı. Bir önceki metaanalizde olduğu gibi transhiyatal özofajektomide anastomoz kaçağı ve reküren larinks sinir hasarı daha fazla bulundu. Transtorasik grupta yoğun bakmı ünitesi ve hastanede kalış zamanı daha uzun, hastane mortalitesi daha fazlaydı. Fakat bu metaanalizde de beş yıllık sağkalımda iki grup arasında fark görülmedi.

Endoskopik olarak özofagus tümörünün trakeobronşiyal invazyonunun görülmesi transhiyatal özofajektomi için kesin kontrendikasyondur. $\mathrm{Bu}$ nedenle üst uç özofagus kanserlerinde preoperatif bronkoskopi ile trakeobronşiyal invazyon ekarte edilmelidir. Patolojik olarak kanıtlanmış karaciğer metastazı, supraklavikular lenf nodu ve diğer uzak organ metastazlarında özofajektomi uygulanmaz. Bilgisayarlı toraks tomografisi (BTT) tümörün lokal yayılımını, pulmoner, hepatik ve diğer intraabdominal uzak lenf nodlarını değerlendirmede önemlidir. Özofagus rezeksiyonundan vazgeçmeden önce genellikle metastaz düşünülen lezyonlardan ince iğne biyopsisi ile patolojik tanı doğrulanmalıdır. BTT özofagus tümörünün aorta, prevertebral fasya veya trakeobronşiyal ağaç ilişkisini gösterebilmesine rağmen, rezektabiliteyi belirlemede güvenilir değildir. Komşu yapılara mevcut invazyon gösterilemeyebilir. Pozitron emisyon tomografisi (PET) rezeksiyonu engelleyecek uzak organ metastazını tespit etmede ve preoperatif evrelemede önemlidir. Özofagusun endoskopik ultrasonografisi (EUS) günümüzde tümör invazyonunun derinliğini ve mediyastinal, paraözofageal, çölyak lenf nodlarını tespit etmede kullanılır. Ancak lümeni tıkalı olgularda kullanılamamaktadır. Baryumlu grafi tümör uzunluğunu, aort ve karinaya yakınlığını, tümöre bağlı özofagus aksında bozulmayı (lokal ekstraözofajiyal yayılmayı düşündüren) görmek için değerlidir. Lokalize tümörlü veya bölgesel lenf nodlarından uzağa yayılmayan tümörlü hastalar özofajektomi adayı olarak düşünülür.

Transhiyatal özofajektomi, radyoterapi, koroziv yanık ve önceden özofagus cerrahisi geçirenlerde de yapılabilir. Özellikle diyafragmatik hiatustan özofagusun palpasyonunda, paraözofajiyal yapışıklıklar belirlenirse, transtorasik yaklaşıma geçebilir. Özellikle akalazya veya özofageal spazm nedeniyle özofagomyotomi uygulanan hastalarda özofajiyal submukoza ve aort etrafında yapışıklık özofagusun künt diseksiyonunda intraoperatif ciddi kanamalara neden olabilir. Transhiyatal özofajektomi yapılan hastalarda önemli kontrendikasyon membranöz trakea veya aorta gibi özofagusa yakın dokularda aşırı fiksasyonun varlığıdır.

Transhiyatal özofajektomi cerrahinin iki temel prensibi olan yeterli ekspojur ve hemostaz göz ardı edilerek yapılır. Cerrah özellikle diyafragmatik hiatusa dar ve derin retraktör yerleştirerek diseksiyonu daha fazla direk görüş altında yapabilir. İntraoperatif kan kayb1 300-500 ml kadar olur, kan transfüzyon ihtiyacı yaygın değildir. Ayrıca bir kanser ameliyatı olarak transhiyatal özofajektomi, doğru evreleme ve komplet mediyastinal lenf nodu diseksiyonunu sağlayamaz. Alt paraözofajiyal ve abdominal lenf nodlarının çıkarılması retrakte hiatustan direk görüşle kolayca başarılabilir. Evreleme için subkarinal lenf nodlarına da erişilebilir. Transhiyatal özofajektomi sonrası sağkalım transtorasik rezeksiyonla benzerdir. Abdominal yaklaşımın ilave avantajları özofajektomi için yeterli ekspojur yanında, ayrıca özofagus yerini alacak gastrointestinal sistem (GIS) parçasının değerlendirilmesine de izin 
verir. Eğer herhangi bir nedenle mide uygun bulunmazsa kolon kolayca mobilize edilerek replasman amacıyla kullanılabilir.

\section{Anestezi}

Hasta supin pozisyonda yatırılır. Kolu cerrahın batın, göğüs ve abdomene ulaşımını engellemeyecek şekilde yanına yerleştirilir. Santral venöz basınç monitarizasyonu için sağ juguler ven kullanılmalıdır. Servikal anastomoz için boynun sol tarafindan girilir. Cerrah transhiyatal diseksiyon sırasında elini posterior mediyastene soktuğunda hipotansiyon gelişebilir. Tansiyon takibi için radyal arter kateteri yerleştirilir. Postoperatif ağrı kontrolü için epidural anestezi uygulanır.

Standart endotrakeal tüple entübasyon yapılır. Transhiyatal diseksiyon sırasında trakea posterior duvarı yırtılabilir. Bu durumda, tüp sol ana bronşa gönderilerek tek akciğer ventilasyonu ile tamir yapılır. Özofajektomi sırasında uzun süreli hipotansiyondan kaçınmak için anestezist ve cerrah arasında yakın kooperasyon gereklidir. Transhiyatal diseksiyon sırasında verilen inhale anestezik ilaçlar, geçici hipotansiyonu önlemek amaciyla kesilebilir ve inspire edilen oksijen konsantrasyonu artırılır. Cerrahi sırasında uzun etkili kas gevşeticilerin dozu minimumda tutulmalı ve hastalar özofajektomi sonrası ameliyat odasında ekstübe edilmelidir. Cerrahi süresince idrar çıkışı takip edilmelidir (Orringer, 2006).

\section{Transhiyatal özofajektomi (Orringer yöntemi)}

Hasta supin pozisyonda iken karın, göğüs ve boyun hazırlanır. Baş sağa dönük ve gerekli halde torakotomi yapılabilecek şekilde hastaya pozisyon verilmiş olmalıdır. Ksifoidden göbeğe kadar uzanan orta hat göbek üstü laparotomi insizyonu ile batına girilir. Otomatik bir batın ekartörü kullanılır. Eksplorasyonda öncelikle rezeksiyona engel olabilecek bir metastaz varlığı (karaciğer metastazı, yoğun çölyak lenf nodu tutulumu ve aortaya tümör invazyonu) ekarte edilir. Mide, replasman organı olarak kullanımını engelleyecek ülser veya kostik yaralanma gibi skar mevcudiyeti açısından değerlendirlir. Daha önce karın cerrahisi geçirmiş hastalarda mide kanlanması tüm damarlar kontrol edilerek değerlendirilmelidir. Batın eksplorasyonu sırasında midenin vasküler yapısının özellikle a. gastrika epiploika dekstranın korunması için dikkatli olunmalıdır (Paç ve Soysal, 2002; Gamniel ve ark., 2011).

Öncelikle karaciğer sol lobu aşağı ve sağa doğru çekilir; sol hepatik ven korunarak trianguler ligament ve diyafram yapışıklıkları elektrokoterle kesilir. Gaz ile sarılmış bir deaver ekartör ile karaciğer sol lobu ve sağ kostal arkus ekarte edilir. $\mathrm{Bu}$ manevra ile mide diyaframdan nazikçe uzaklaştırılarak hiatus eksplore edilir. Frenoözofageal membran özofagus duvarından künt ve keskin diseksiyon ile ayrılır. Özofagus önünden mediyastene doğru hiatus içinden künt diseksiyon ile dokular ayrılır. Eğer tümör distal özofagusta yerleşik ise tümörün çevre dokular ile ilişkisi kolayca değerlendirilebilir. İntraabdominal özofagus dönülerek penröz bir drenle asılır. Gastrohepatik ligamentin alt bölümü diseke edilerek açılır ve yukarıya özofagusa doğru diseke edilerek genişletilir. Diseksiyon sırasında bu bağ içinde yerleşik olan aberan sol hepatik arter bağlanır. Böylece diyaframın sağ krusu ortaya çıkar. Krusun anterior ve mediyal kenarları diseke edilerek, frenoözofajiyal membran özofagustan tamamen ayrilır. Bu işlemlerin sonunda 5-10 cm distal özofagus mobilize edilmiş olur. Posterior mediyastende özofagus mobilitesi değerlendirlir.
Tümörün mediastinal dokularla ilişkisi, çevre dokulara, aortaya, prevertebral fasyaya fikse olup olmadığı kontrol edilir. Özofagusun mobilitesi değerlendirilip, herhangi bir invazyon bulgusuna rastlanmazsa transhiyatal rezeksiyonun mümkün olabileceğine karar verilir (Paç ve Soysal, 2002; Orringer, 2006).

Midenin serbestleştirilmesi; nazogastrik tüp, ucu pilorda olacak şekilde midenin büyük kurvaturu boyunca yerleştirilir (Gamniel ve ark., 2011). Bu aşamada omentum majus ve omentum minusun diseke edilip klemple mide çevresinden dönülerek slikon drenle askıya alınması diseksiyonu kolaylaştırır. Büyük kurvaturda gastroepiploik arter seyri ve çapı hastadan hastaya değişiklik gösterebilir. Gastroepiploik arter tüm seyri boyunca zedelemeden korunarak midenin iskeletizasyonu sağlanır. Büyük kurvaturda gastroepiploik arter seyri sonlandıktan sonra kardiaya doğru tüm kısa gastrik arterler tek tek ve mideye yakın olarak bağlanır (klips veya ligasure de kullanılabilir) ve kesilir. Mide ve dalak korunarak dalak hilusu ve diyafram kuruslarına yakın iki kısa gastrik arter de dikkatlice bağlanıp kesilmelidir. Kısa gastrik arterler bağlanmadan önce dalak kapsülü ve omentum arasındaki yapışıklıklar ayrılırsa dalak kapsülünde yırtılma ve kanama riski önlenmiş olur. Gastroepiploik arkus korunarak büyük kurvatur mobilizasyonu tamamlandıktan sonra gastrokolik omentum dikkatlice kesilir ve ayrılır. Bu sırada a. kolika medianın ve kolon mezosunun zedelenmemesine dikkat edilmelidir. $\mathrm{Bu}$ vasküler hat kısa gastrik arterlerden pilora kadar devam etmektedir. Omentum majus içindeki küçük damarlar koterize edilebilir. Pilora yakın alanda bulunan gastroepiploik arterin başlangıç bölümü diseksiyon sırasında korunmalıdır (Paç ve Soysal, 2002; Orringer, 2006).

$\mathrm{Bu}$ aşamalardan sonra mide öne doğru çekilir. Küçük omental kese eksplore edilir. Mide arka duvarı ile pankreas arasındaki yapışıklıklar ayrılır. Sol gastrik arter ve ven midenin öne doğru çekilmesi ile ortaya çıkar. Mide arkaya ve aşağı çekilerek de sol gastrik arter ve ven eksplore edilebilir. Sol gastrik arter ve ven çift bağlanıp transfiksiyon dikişi ile desteklendikten sonra kesilmelidir. En son kapatma sırasında damar güdükleri tekrar kontrol edilmelidir. Midenin çekilmesi gerilmesi gibi tüm manipulasyonlar sırasında geri kalan tüm arteriel sistem dikkatlice korunmalıdır. Bu sırada özellikle sağ gastrik arter yaralanabilir.

Alt özofagus kanserlerinde, hatta bazen üst özofagus kanserlerinde, sol gastrik arter etrafindaki lenf nodlarına metastaz olabilir. Arterin çıkış yerine yakın bağlanırsa mideye bitişik lenf nodları daha sonra mide üzerinden diseke edilebilir. Sol gastrik arterin proksimalindeki ve sağ diyafram krusu önündeki yağ dokusu ve lenfatikler mide ile birlikte diseke edilir (Orringer, 2006).

Midenin daha fazla mobil hale getirilebilmesi için Kocher manevrası ile doudenokolik bantlar ayrılıp doudenum iki bölümü serbestleştirilerek pilor sağ üst kadrana, ksifoidin altına getirilebilir. Midenin daha yukarı çekilmesi planlanıyorsa bu manevranın yapılması gerekebilir (Gamniel ve ark., 2011).

Pilöromiyotomi endikasyonu tartışmalıdır. Önceleri özofajektomiler sırasında vagotomi ve GIS' in anatomik yapısının değişiminden doğan gastrik boşalma hızındaki yavaşlamadan doğabilecek sorunları engellemek için piloromiyotomi rutin olarak yapılırken, son zamanlarda dumping sendromu, diare ve fistül gibi komplikasyonlar nedeniyle uygulama sınırlanmıştır (Yannopoulos ve ark., 2009). 
Uygulamalarımızda pilor genişliği işaret parmak geçişine izin veriyorsa $(\sim 1,5 \mathrm{~cm}$ çap) piloromiyotomi yapılmamaktadır. Aksi halde piloromiyotomi önerilmektedir. Ploromiyotomi için pilorun distalinden başlanarak submukoza ve mukozanın fitıklaştı̆̆ görülene kadar kas tabakası diseke edilir. Mukozaya inildikten sonra miyotomiye doudenuma kadar devam edilir. Toplam 1,5-2 cm uzunluğunda bir miyotomi yapilır. Bunun $1 \mathrm{~cm}$ si mide, $0,5-1 \mathrm{~cm}$ si doudenum üzerindedir. Doudenum mukozası daha frajil olduğundan bu bölgeye yaklaşınca daha dikkatli olunmalıdır. Herhangi bir mukozal hasar oluşursa primer tamir edilebilir. Tamir sonrasında bölge omentum ile desteklenebilir. Orringer ve ark. (2007) transhiyatal özofagus rezeksiyonunun değerlendirlidiği bir çalışmada, tüm hastalara piloromiyotomi uygulamışlardır (Orringer ve ark., 2007).

Mide serbestleştirilmesi tamamlandıktan sonra hiatus tekrar eksplore edilerek, anterior krus uygun klemple dönülerek kesilir ve hiatus genişletilir. Özofagus çevresindeki ask1 aşağı doğru çekilerek özofagusun lateral ve anterior duvar1nın eksplorasyonu için uygun görüş sağlanmış olur. Özofagus, mediyasten ve plevra arasındaki yapışıklıklar bir harmonik skalpel kullanılarak ya da klipslenerek ayrılır. Özofagus ön duvarı ile retrokardiak alan arasındaki, arka duvar ile aort ve mediyasten arasındaki yapışıklıklar künt parmak diseksiyonu ile ayrılır. Görmeden yapılan tüm diseksiyonlarda daha dikkatli olunmalı aşırı ve tehlikeli olabilecek hareketlerden sakınılmalıdır. Diseksiyon esnasında meydana gelebilecek minimal kanamalar ekspanse olan akciğer dokusu ve toraksa yerleşen mide dokusunun baskısı ile kontrol altına alınır. Bazen aorttan alt özofagusa gelen büyük bir arter dalı olabilir. Bu nedenle eğer mümkünse bu bölge direkt görüş altında diseke edilmelidir. Alt özofagus kanserlerinde mediastinal tutulum varsa yine görerek bu alan diseke edilip tümör çevre dokudan güvenle ayrllabilir. Tümör plevra perikard ve diafragmaya invaze ise tümör bu dokular ile birlikte çıkartılmalıdır. Bu bölgeden daha yukarıda karina seviyesine yakın bir alanda yerleşik tümörlerde transhiyatal yol tercih edilmemelidir (Orringer, 2006).

\section{Servikal diseksiyon}

Boynun sol tarafinda; insusura jugularisten başlayıp sternokleidomastoid kasin anterior kenarına paralel yukar1da krikoid kıkırdağa doğru devam eden 5-6 cm lik cilt insizyonu yapılır. Platisma ve omohiyoid kas tabakaları kesilir, sternokloidomastoid kas ve karotis kıllfı nazikçe dar bir tiroit ekartörü kullanılarak laterale çekilir. Tiroit sol lobu ve trakea ekartör kullanmadan sadece parmakla mediyale ekarte edilir. Mediyalde tiroit ve trakea lateralde karotis kılıfı arasındaki yapışıklılar bir fındık tampon yardımı ile dikkatli bir şekilde diseke edilir. İnferior tiroit arter ve mediyal tiroit ven güvenli diseksiyona engel teşkil ederse bağlanabilir. Trekeoözofajiyal sulkusa, sol inferior larinks sinirinde meydana gelebilecek bir hasarı engellemek için, kesinlikle metal ekartör kullanılmamalıdır. Diseksiyonlar sırasında siniri korumak için azami derecede dikkatli olunmalıdır. Bu esnada özofagusa yerleştirilecek bir nazogastrik sonda özofagus eksplorasyonunda faydalı olacaktır. Diseksiyon özofagus lateralinden prevertebral fasyaya doğu devam ettirilir. İşaret parmağı diseksiyonu ile prevertebral retroözofajiyal avasküler fasia süperior mediyastene doğru diseke edilir. Diseksiyondan sonra işaret parmağ 1 ile özofagus trakeoözofajiyal oluktan yukarıya krikoid karti- laj seviyesine kadar diseke edilir. Trakea ve özofagus arasındaki plan künt ve keskin diseksiyonla açılır. Bu diseksiyon sırasında trakeoözofajiyal oluğun posteriorunda muhtemel bir larinks siniri hasarından korunmak için dikkatli olunmalıdır. Servikal özofagus etraf yumuşak dokudan künt diseksiyon ile ayrılarak tüm çevresi dönülür ve bir silikon drenle asılır. Bu sırada membranöz trakeanın zedelenmemesine dikkat edilmelidir. Bu aşamalardan sonra üst torasik özofagus karina seviyesine kadar çepeçevre mobilize edilmiş olur (Paç ve Soysal, 2002; Orringer, 2006; Gamniel ve ark., 2011).

\section{Mediastinal (transhiyatal) diseksiyon}

Transhiyatal diseksiyon mutlaka kurallara uygun bir sira dahilinde yerine getirilmelidir. Önce özofagusun posterior yüzü, sonra anterior yüzü, en son lateral yüzü mobilize edilmelidir. Sol el ile gastroözofajiyal bileşkede özofagusu saran dren aşağı doğru çekilir. Önce el sonra ön kol posterior mediyastene sokulabilecek hale gelene kadar sağ el hiatustan özofagus arkasina doğru sokularak künt diseksiyonla hiatus iyice dilate edilir.

Transhiyatal diseksiyon bittiğinde boyuna dönülür. Daha önceden diseke edilen üst torasik girişten parmak diseksiyonu ile özofagus çepeçevre serbest hale getirilir. İnsizyondan aşağ 1 bir monte tampon yardımı ile prevertebral plandan inferiore doğru ilerlenir. Bir el hiatustan yukarı özofagusun posterioruna, diğer el ise prevertebral plandan aşağı doğru ilerletilir. Bu sırada servikal ve abdominal özofagusun etrafinda yerleşik olan pernöz drenlere traksiyon uygulanması diseksiyonu kolaylaştırabilir. İki el retroözofajiyal alanda birleşene kadar superiorden ve inferiorden diseksiyon devam ettirilir. Bu sirada anestezi ile koopere olunmalıdır. El kalbe bası yapacağından cerrah sürekli olarak monitörden tansiyonu ve kalp ritmini izlemeli; aralıklı olarak mediyastenden çıkarılmalı ve kalp ritmi ve tansiyonun normale dönmesi beklenmeli ve mümkün olduğunca hızlı çalışılmalıdır. Parmak ucu ile künt diseksiyon yapılarak özofagus ön duvarı membranöz trakeadan ve perikarddan sıyrılır ve batına çekilir. Nervus vaguslar özofagus ve midenin tamamen serbest kalması için lateral diseksiyon sırasında kesilir (Orringer, 2006).

Servikal ve hiyatal bölgede diseksiyon sırasında mediastinal yapılardan özogafusa gelen bantlar ve yapışıklıklar parmak ucuyla dikkatli bir şekilde ayrılır. Servikal bölgeden özofagus yukarı çekilip, mide yukarı rahat bir şekilde geldiğinde diseksiyon tamamlanmış olur.

Özofagusun mediyastende diseksiyonu tamamlandiktan sonra posterior mediyasten ekartasyonla gözlemlenir ve abondan bir kanama ya da büyük bir hava kaçağı olup olmadığına bakılır. Mide batına çekilir. Distal özofagustaki tümörle gastrik rezeksiyon hattı arasında 5-6 cm uzaklık olacak şekilde mide rezeksiyon hattı oluşturulur. Mide damar yapısı incelenerek, büyük kurvaturdan gelen damarların seyri göz önünde bulundurularak rezeksiyon hattı kontrol edilir. Rezeksiyonun bağlanmış olan sol gastrik arterin distalinde kalmasına özellikle dikkat edilmelidir. Böylece sol gastrik arter tarafindan beslenen mide bölgesi rezeke edilerek olası bir iskeminin önüne geçilmiş ve sol gastrik lenf nodları da çıkarılmış olacaktır. Midenin efektif bir şekilde tüpleştirilmesini sağlamak için küçük kurvaturu da içine alacak şekilde rezeksiyonun gerçekleştirilmesi uygundur. Rezeksiyon lineer stapler ile yapılır. Kesme işlemi sırasında mide fundustan tutularak düz hale getirilir. Genellikle proksimal gastrekto- 
miden sonra tüpleşen mide boyna kadar uzanabilse de; bu aşamada kalan midenin boyna uzanabilirliği kontrol edilerek rezeksiyon yapılmalıdır. Rezeksiyon sonrası stapler hattı tek tek veya devamlı ipek, vikril ya da propilen dikişler ile desteklenir (Paç ve Soysal, 2002). Klinik uygulamalarda, stapler hattının köşeleri mide duvarına gömülür. Proksimal köşede anastomoz lateralinde kalacak bölgede birkaç kez sirküler seroza dikişleri ile lümen içine duvarı gömerek postoperatif reflünün önlenmesi amacıyla glob oluşturması tercih edilir (Yalav, 2001).

Midenin yukarı çekilmesinden önce künt parmak diseksiyonu ile posterior mediyastende midenin yerleşeceği tünel hazırlanır. Hiatus dar bir deaver ekartör ile eleve edilerek mide posterior mediyastene doğu yukarıya nazikçe yerleştirilir. Bu aşamada midede oluşabilecek travmayı en aza indirmek amaciyla mide üzerine dren dikilmemeli ve mediyastenden geçiş esnasında aspirasyon uygulanmamalıdır. Biz mide fundusunu özofagus güdüğüne geçici 2 numara ipek dikiş ile sütüre ettikten sonra, yukarı çekilmesi yerine, elle posterior mediyastende aortik arkın altından yukarı doğru itilerek servikal insizyondan çıkarılmasını öneriyoruz. Mide servikal insizyondan görünür görünmez mide yaralanmasına neden olmamak için mide tepesi parmak uçları ile yakalanır ve boyun insizyonuna yerleştirilir. Alttaki el posterior mediyastenden çekilir ve geçici sütürler alınır.

Toraks içindeki midenin bükülmesini önlemek için, stepler hattı hastanın sağ tarafında kalacak şekilde, intratorasik midenin anterior yüzü hiatus ve servikal insizyondan iyice palpe edilerek yerleştirilir. Mide tepesinin travmasını engellemek için mide prevertabral fasyaya dikilmez. İntraoral içerik tarafından abdomenin kontaminasyonunu önlemek için batın insizyonu tamemen kapatılana kadar gastroözofajiyal anastomoza başlanmaz. Kanama kontrolü, özellikle dalak loju iyice kontrol edilerek, yapıldıktan sonra, hiatus üç parmağın kolaylıkla geçebileceği şekilde 0 numara ipek dikiş ile daraltılır. Piloromiyotomi sahası komşu omentum ile sarılarak desteklenir. Sol karaciğer lobu normal pozisyonuna getirilir. Sol üst kadrandan dışarı açılacak şekilde beslenme jejunostomisi gerçekleştirilir ve abdominal insizyon kapatılır ve steril bir örtü yada havlu ile sarılarak sahadan izole edilir. $\mathrm{Bu}$ aşamadan sonra gastroözofajiyal anastomozun yapılacağ1 boyun bölgesine geçilir (Paç ve Soysal, 2002; Orringer, 2006; Gamniel ve Krasna, 2011).

\section{Servikal gastroözofajiyal anastomoz}

Mide uygun şekilde mobilize edilip boyuna çekilerek 4-5 $\mathrm{cm}$ lik mide tepesi klavikula seviyesi üzerinde prevertebral fasyanın karşısına ve servikal özofagusun arkasında boyna yatırılır. Özofagusun ucu allis klembi ile tutulup kaldırılır. Mide uygun bir klemp ile tutulur özofagus aşağı çekilerek mide üzerinde anastomoz sahası belirlenir. Bu alana elektrokoter ile 1,5-2 cm lik vertikal bir gastrostomi yapılır.

Özofajiyal stepler dikiş hattı iki allis klembi ile tutularak aşağıya çekilir. Özofagusun anastomoz seviyesi belirlenerek, özofagus oblik olarak debakey forsepsi ile tutulur ve bu forseps kılavuz alınarak forsepsin altından özofagus kesilir ve çıkartılır. Anastomoz üzerindeki gerginliği minimale indirmek için kalan özofagusun aşırı kısaltılmasından kaçınmak gerekir. Eğer kalan özofagus anastomoz için çok kısa olursa fonksiyonel sonuçlar iyi olmayabilir.

Uç-yan anastomoz için stepler yerleştirilmeden önce özo- fagus ucu posterior duvarı ve mide anterior duvarında oluşturulan gastrostominin üst ucu bir askı sütürüyle yaklaştırılır. İkinci sütür kesilmiş özofagusun anterior tepesinden geçirilir. Her ikisine sürekli aşağı doğru traksiyon uygulanırken endo steplerının kesici ucu mide içinden sokulur ve steplerin daha kalın olan diğer parçası özofagus içinden geçirilir. Steplerin kolları yavaş yavaş yaklaştırılr ve dikkatli bir şekilde anterior gastrik duvar ile posterior özofageal duvar birbirine hizalanır. Stepler bıçakları ilerletir ve anterior mide duvarı ile posterior özofagus duvarını birleştiren üç $\mathrm{cm}$ uzunluğunda uç-yan bir anastomozun arka duvarı yapılmış olur. Stepler sahadan çekilir. Bir nazogastrik tüp anestezist tarafindan cerrahın klavuzluğunda yerleştirlir. 4/0 polidiakson (PDS) sütur mide ve özofagusun her ikisinden de geçmek üzere köşeye yerleştirilir. Açık olan özofagus ve mide kenarları 4/0 monoflaman absorbabl dikiş ile iki tabaka halinde yaklaştırılır. İlk tabaka tam kat devamlı sütur seklinde atılır. İkinci tabaka tek tek dikişlerden oluşturulur. Bir gümüş metal hemostatik klip süturlerin iki taraflı her iki köşesine yerleştirilir ve kesilir (Orringer, 2006).

$\mathrm{Bu}$ klipler postoperatif takipler esnasında anastomozun takibinde marker olarak kullanılırlar. Servikal yara yıkanır,1/4 inch plastik dren yaranın tabanına yerleştirilir. Muskuler tabaka 3-0 emilebilir dikiş ile tek tek kaptılır. Cilt 4-0 naylon dikişle devamlı olarak kapatılır. Operasyon odasında olası bir hemopnömotoraksı ekarte etmek ve akciğerin tam ekspansiyonunu görmek için portabl makine ile bir göğüs radyografisi çekilir (Paç ve Soysal, 2002; Orringer, 2006; Gamniel ve ark., 2011).

\section{Komplikasyonlar}

Transhiyatal diseksiyon sırasında bir ya da iki plevral kavitenin birden açılması trakeobronşial ağaçta hasar, kanama ve dalak yaralanması transhiyatal özofagus rezeksiyonu sırasinda meydana gelebilecek intraoperatif komplikasyonlardır (Orringer, 2006).

Transhiyatal özofajektomi esnasında trakeal yırtık nadiren oluşur. Oluşursa genellikle küçüktür, lineerdir ve posterior membranöz trakeadadır. Trakeada oluşan bir hasar transhiyatal diseksiyon sırasında hem hiatustan hem de boyundan hava kaçağının görülmesi ile anlaşılır. Hava kaçağı büyükse endotrakeal tüpün balonu indirilir diafragmatik hiatustan el sokularak sol ana bronş içine yerleştirilir. Böylece daha kontrollü bir şekilde tek akciğer ventilasyonu yapılmış olur. Ek olarak parsiyel bir üst sternum kesisi direkt tamir için membranöz trakeanın daha iyi görülmesini sağlayabilir. Trakea tamirine başlamadan önce eğer mümkünse mebranöz trakeanın daha iyi görülebilmesini sağlamak için transhiyatal özofajektomi tamamlanmalıdır. Daha büyük yırtıklar sağ torakotomi ile primer tamir gerektirir (Orringer, 2006).

Uygun hasta seçimi yapılması halinde transhiyatal rezeksiyonlarda çok fazla kanama beklenmez. Eğer diseksiyon s1rasinda bir kanama meydana gelirse boyun insizyonundan bir aspiratörle posterior mediyasten temizlenir ve aortanın anterior yüzü doğrudan kontrol edilir. Eğer bu teknikle kanama kontrolü mümkün değilse büyük batın kompresleri posterior mediyastene doldurulur. Birkaç dakika beklenir. Mediyasten tekrar açılmadan önce intravasküler volüm replase edilir. Eğer kanama devam ediyorsa kompresler tekrar konur batın hızla kapatılır hastaya torakotomi pozisyonu verilir. Ĕger kanama alt 1/3 özofagusun diseksiyonu sırasında oluşmuşsa sol, üst 
ya da orta özofagusun diseksiyonu sırasında oluşmussa sağ torakotomi pozisyonu verilmelidir. Mide mobilizasyonu esnasında dalak yaralanması olabilir. Bu durumda splenektomi yapılmalıdır (Paç ve Soysal, 2002; Orringer, 2006).

Postoperatif ses kısıklığının devam etmesi sol larinks siniri hasarının belirtisidir. Larinks sinir hasarı düşünüldüğünde durum laringoskopi ile doğrulanmalıdır. Eğer sol vokal kord paralitikse hasta postoperatif iyi öksüremez ve sekresyonlar iyi temizlenemez. Bu durumda hastanın yoğun solunum fizyoterapisine ihtiyacı olacaktır. Oral beslenme başlatıldığında hasta katı gıdaları daha iyi tolere edebilirken; sıvı gıdaları aspirasyona meyillidir. Sinir yaralanmalarının çoğu peroperatif gerginlik ve aşırı basılara bağlı geliştiğinden bu hastaların (\% 70'inde) 2-3 ayda şikayetler kendiliğinden düzelebilmektedir (Paç ve Soysal, 2002).

Postoperatif 48 saatten sonra hastanın ateşi $38^{\circ} \mathrm{C}$ üzerine çıkarsa, bu aksi ispat edilene kadar anastomoz kaçağını düşündürmelidir. Servikal yara inflame olsun yada olmasın kontrastlı radyolojik inceleme yapılmalıdır. Gastrografin gibi suda çözünen kontrast ajanlar eğer aspire edilirse şiddetli pnömoniye neden olurlar bu nedenle dikkatli olunmalıdır. En iyi seçenek dilüe halde baryum kullanmaktır. Ayrıca bununla mukoza detayları daha iyi görülebilir. Hasta kontrast maddeyi yutarken servikal yara etrafindan ya da drenden geliyorsa, anastomozda kaçak olduğu anlaşılır. Bu durumda yara hemen açılmalı ve fistülün mekanik temizliği iyi bir şekilde yapılmalıdır. Açık servikal yara günde birkaç kez nemlendirilmiş gazlar ile pansuman edilip kapatılır. Servikal anastomoz kaçaklarının çoğu bir haftada spontan olarak kapanır (Orringer, 2006; Gamniel ve Krasna, 2011).

Anastomoz kaçağı striktür gelişimi için predispozan bir patolojidir. Hastalar tipik olarak postoperatif 2-3. ayda ilerleyen disfaji şikayeti ile başvururlar. Anastomoz kaçağ1 ve anastomozun manuel yapılması striktür gelişimi için risk faktörleridir. Özofajektomi sonrası anastomoz darlığı oranı \% 5-30 arasında bildirilmektedir. Özellikle küçük çaplı (25- 27 $\mathrm{mm}$ ) sirküler staplerlerin kullanıldığı anastomozlarda darlık oranı yüksektir. Darlık geliştiğinde, fibrozis gelişmeden erken dilatasyon önerilmektedir (Kotan ve ark., 2001).

Transhiyatal özofajektomilerden sonra \% 0,6-4 oranda şilotoraks meydana geldiği bilidirilmektedir. Göğüs tüpünden uzamış ve fazla sıvı drenajı ile (8 saatte 200-400 ml) karakterizedir. Şilotoraks şüphesi varsa, jejunostomiden krema verilir eğer şilotoraks varsa gögüs tüpünden gelen serohemorajik sıv1 vasfı süt kıvamı ve rengine dönecektir. Konservatif takip ile kaçak kesilmezse jejunostomiden krema verilerek şilöz kaçağın yeri belirlenir ve transtorasik yaklaşımla kaçak yeri tamir edilir (Guo ve ark., 2011).

\section{Postoperatif bakım}

Pulmoner fizyoterapi özofajektomi yapılan hastalarda postoperatif erken dönemde çok önemlidir. Üst özofajiyal sfinkteri sağlam olduğu için genellikle aspirasyon izlenmez. Ancak gastrik tüp aperistaltiktir ve mide boşalması yer çekimi ile sağlanır. Bu nedenle hastalar intratorasik midenin rahat boşalabilmesi için ters trandelenburg pozisyonunda yatırılmalıdir.

İlk 24-48 saatte supraventriküler aritmiler sık görüldüğü için hasta monitörize edilerek kalp ritmi yakından takip edilmelidir (Paç ve Soysal, 2002).

İntraoperatif olarak yerleştirlen jejunostomi tüpünden 24 saat sonra $30 \mathrm{ml} /$ saat dozunda beslenme mayisi başlanır. 12 saatte bir, kademeli olarak artırılarak optimum doza çıkılır. Postoperatif bir hafta sonra ek sorun yoksa oral olarak metilen mavisi içirilir. Eğer boyundaki drenden metilen mavisi ile boyalı sıvı drenajı olmazsa nazogastrik tüp ve dren çekilir. Oral su alımı başlatılır. Sonrasında kademeli olarak tanesiz sıv1 gıdalar ve yumuşak vasıflı gıdalar verilir. Oral beslenmeye geçilince jejunostomiden verilen beslenme mayisinin volümü kademeli olarak azaltılarak kesilir. Hastanın özellikle yemek sonrasında hemen yatmaması az az ve sık sık gida alması önerilmelidir. Hastalar ortalama 10-15. günde taburcu edilir. Birinci ayda beslenme jejunostomisi çekilir (Riccardi ve ark., 1999).

\section{KAYNAKLAR}

Barreto, J.C., Posner, M.C., 2010. Transhiatal versus transthoracic esophagectomy for esophageal cancer. World J. Gastroentero. 14, 38043810 .

Birkmeyer, J.D., Siewers, A.E., Finlayson, E.V., Stukel, T.A., Lucas, F.L., Batista, I., Welch, H.G., Wennberg, D.E., 2002. Hospital volume and surgical mortality in the United States. N. Engl. J. Med. 346, 1128-1137.

Denk, W., 1913. Zeure Rudikal Operation DesOoesophagus Karzinoms vor loutige mitteilung zbl. Chir. 40 , 1965.

Gamniel, Z., Krasna, M., Çev:Laçin, T., 2011. Transhiatal özofajektomierişkin Göğüs Cerrahisi Ed: David Sugerbaker. Çev. Ed: Mustafa Yüksel. İstanbul Nobel Tip Kitapevi. pp. 131-140.

Gelfand, G.A., Finley, R.J., Nelems, B., Inculet, R., Evans, K.G., Fradet, G., 1992. Transhiatal esophagectomy for carcinoma of the esophagus and cardia. Experience with 160 cases. Arch. Surg. 127, 1164-1167.

Goldminc, M., Maddern, G., Le Prise, E., Meunier, B., Campion, J.P., Launois, B., 1993. Oesophagectomy by a transhiatal approach or thoracotomy: A prospective randomized trial. Br. J. Surg. 80, 367-370.

Guo, W., Zhao, Y.P., Jiang, Y.G., Niu, H.J., Liu, X.H., Ma, Z., Wang, R.W., 2011. Prevention of postoperative chylothorax with thoracic duct ligation during video-assisted thoracoscopic esophagectomy for cancer. Surg. Endosc. 11, 2032-2033.

Hulscher, J.B., Tijssen, J.G., Obertop, H., van Lanschot, J.J., 2001. Transthoracic versus transhiatal resection for carcinoma of the esophagus: A meta-analysis. Ann. Thorac. Surg. 72, 306-313.

Hulscher, J.B.F., van Sandick, J.W., Tijssen, J.G.P., Obertop, H.J., van Lanschot, J.B., 2000. The recurrence pattern of esophageal carcinoma after transhiatal resection. J. Am. Coll. Surg. 191, 143-148.

Jacobi, C.A., Zieren, H.U., Müler, J.M., Pichlmaier, H., 1997. Surgical therapy of esophageal carcinoma: The influence of surgical approach and esophageal resection on cardiopulmonary function. Eur. J. Cardiothorac. Surg. 11, 32-37.

Kotan, Ç., Kilsi, E., Sönmez, R., Aslan, M., Aras, A., Arslantürk, H., Söylemez, Ö., 2001. Özofagus kanserinin cerrahi tedavisinde deneyimimiz: 57 olgunun analizi. Van Tip Dergisi. Cilt: 8, Say1: 2, 54-60.

Orringer, M.B., Sloan, H., 1978. Esophagectomy without thoracotomy. J. Thorac. Cardiov. Sur. 76, 643-654.

Orringer, M.B., Marshall, B., Chang, A.C., Lee, J., Pickens, A., Lau, C.L., 2007. Two thousand transhiatal esophagectomies: Changing trends, lessons learned. Ann. Surg. 246, 363-372. 
Orringer, M.B., 2006. Transhiatal esophagectomy. In: Operative Thoracic Surgery; ed. Kaiser, L.R., Jamieson, G.G., Edward Arnold Ltd. London. Fifth edition. pp. 317-412.

Paç, M.,Soysal, Ö., 2002. Transhiatal özofajektomi. Özofagus hastalıklarının tıbbi ve cerrahi tedavisi. Ed: Mustafa Yüksel, Ahmet Başoğlu. İstanbul Bilmedya grup. pp. 259-274.

Riccardi, D., Allen, K., 1999. Nutritional management of patients with esophageal and esophagogastric junction cancer. Cancer Cause. Control. 6, 64-72.

Rindani, R., Martin, C.J., Cox, M.R., 1999. Transhiatal versus Ivor-Lewis oesophagectomy: Is there a difference? Aust. N.Z.J. Surg. 69, 187194.

Yalav E, 2001. Özofagus kanserinin cerrahi tedavisi. Göğüs Cerrahisi. Ed: Mustafa Yüksel, Göksel Kalayc1. Bilmedya Grup. pp. 879-889

Yannopoulos, P., Theodoridis, P., Manes, K., 2009. Langenbecks Esophagectomy without thoracotomy: 25 years of experience over 750 patients. Langenbecks Arch Surg. 394, 611-616. 